\title{
Correction to: Use of non-Gaussian time-of-flight kernels for image reconstruction of Monte Carlo simulated data of ultra-fast PET scanners
}

\author{
Nikos Efthimiou ${ }^{1,2,3^{*}} \mathbb{0}$, Kris Thielemans ${ }^{4}$, Elise Emond ${ }^{4}$, Chris Cawthorne ${ }^{5,6}$, Stephen J. Archibald ${ }^{1}$ and \\ Charalampos Tsoumpas ${ }^{2,7}$
}

The original article can be found online at https://doi.org/10. 1186/s40658-020-00309-8

\section{${ }^{*}$ Correspondence:}

efthymin@pennmedicine. upenn.edu

1 PET Research Centre, Faculty of Health Sciences, University of Hull, Cottingham Rd,

Hull HU6 7RX, UK

Full list of author information is available at the end of the article

\section{Correction to: EJNMMI Phys (2020) 7:42 \\ https://doi.org/10.1186/s40658-020-00309-8}

Following publication of the original article [1], two typographical errors were found by the authors in formulas 6 of the main text and 19 in the appendix. The original and correct versions of the equations are given below:

Original formula 6: $F_{D}(d ; \lambda)=\left(\frac{1-\operatorname{sgn}(d)}{2}-\operatorname{sgn}(d)(\cosh (\lambda(T-|d|))-1) \operatorname{csch}\left(\frac{T \lambda}{2}\right)^{2}\right) / 4$.

Correct formula 6: $F_{D}(d ; \lambda)=\frac{1+\operatorname{sgn}(d)}{2}-\operatorname{sgn}(d)(\cosh (\lambda(T-|d|))-1) \operatorname{csch}\left(\frac{T \lambda}{2}\right)^{2} / 4$.

Original formula 19: $H=\exp (2 d \lambda)(E+F)$.

Correct formula 19: $H=\exp (2 d \lambda)(-E+F)$.

The original article [1] has been corrected.

\section{Author details}

${ }^{1}$ PET Research Centre, Faculty of Health Sciences, University of Hull, Cottingham Rd, Hull HU6 7RX, UK. ${ }^{2}$ Biomedical Imaging Science Department, School of Medicine, University of Leeds, Leeds, UK. ${ }^{3}$ Department of Radiology, Perelman School of Medicine, University of Pennsylvania, 156B John Morgan Building, 3620 Hamilton Walk, Philadelphia, PA 19104-6055, USA. ${ }^{4}$ Institute of Nuclear Medicine, University College London, London, UK. ${ }^{5}$ Nuclear Medicine and Molecular Imaging, Department of Imaging and Pathology, KU Leuven, Leuven, Belgium. ${ }^{6}$ Molecular Small Animal Imaging Centre, KU Leuven, Leuven, Belgium. ${ }^{7}$ Invicro, Hammersmith Hospital, London, UK.

Published online: 24 February 2022

Reference

1. Efthimiou N, Thielemans K, Emond E, et al. Use of non-Gaussian time-of-flight kernels for image reconstruction of Monte Carlo simulated data of ultra-fast PET scanners. EJNMMI Phys. 2020;7:42. https://doi.org/10.1186/ s40658-020-00309-8.

\section{Publisher's Note}

Springer Nature remains neutral with regard to jurisdictional claims in published maps and institutional affiliations. author(s) and the source, provide a link to the Creative Commons licence, and indicate if changes were made. The images or other third party material in this article are included in the article's Creative Commons licence, unless indicated otherwise in a credit line to the material. If material is not included in the article's Creative Commons licence and your intended use is not permitted by statutory regulation or exceeds the permitted use, you will need to obtain permission directly from the copyright holder. To view a copy of this licence, visit http:// creativecommons.org/licenses/by/4.0/. 